\title{
Edible red seaweed Campylaephora hypnaeoides J. Agardh alleviates obesity and related metabolic disorders in mice by suppressing oxidative stress and inflammatory response
}

Shigeru Murakami ${ }^{1 *} \mathbb{D}$, Chihiro Hirazawa ${ }^{1}$, Rina Yoshikawa ${ }^{1}$, Toshiki Mizutani ${ }^{1}$, Takuma Ohya ${ }^{1}$, Ning Ma², Takahiko Ikemori ${ }^{3}$, Takashi Ito ${ }^{1}$ and Chiaki Matsuzaki ${ }^{4}$

\begin{abstract}
Background: The obesity epidemic has become a serious public health problem in many countries worldwide. Seaweed has few calories and is rich in active nutritional components necessary for health promotion and disease prevention. The aim of this study was to investigate the effects of the Campylaephora hypnaeoides J. Agardh (C. hypnaeoides), an edible seaweed traditionally eaten in Japan, on high-fat (HF) diet-induced obesity and related metabolic diseases in mice.

Methods: Male C57BL/6J mice were randomly divided into the following groups: normal diet group, HF diet group, HF diet supplemented with 2\% C. hypnaeoides, and HF diet supplemented with 6\% C. hypnaeoides. After 13 weeks of treatment, the weight of the white adipose tissue and liver, and the serum levels of glucose, insulin, adipokines, and lipids were measured. Hepatic levels of adipokines, oxidant markers, and antioxidant markers were also determined. Insulin resistance was assessed by a glucose tolerance test. Polysaccharides of $C$. hypnaeoides were purified and their molecular weight was determined by high-performance seize exclusion chromatography. The anti-inflammatory effects of purified polysaccharides were evaluated in RAW264.7 cells.

Results: Treatment of HF diet-induced obese mice with C. hypnaeoides for 13 weeks suppressed the increase in body weight and white adipose tissue weight. It also ameliorated insulin resistance, hyperglycemia, hepatic steatosis, and hypercholesterolemia. The ingestion of an HF diet increased serum levels of malondialdehyde (MDA), tumor necrosis factor a (TNF-a), and monocyte chemoattractant protein-1 (MCP-1), while it decreased serum adiponectin levels. In the liver, an HF diet markedly increased the MDA, TNF-a, and interleukin-6 (IL-6) levels, while it decreased glutathione and superoxide dismutase. These metabolic changes induced by HF diet feeding were ameliorated by dietary C. hypnaeoides. Purified polysaccharides and ethanol extract from C. hypnaeoides inhibited the lipopolysaccharide-induced overproduction of nitric oxide and TNF-a in macrophage RAW264.7 cells.
\end{abstract}

*Correspondence: murakami@fpu.ac.jp

${ }^{1}$ Department of Bioscience and Biotechnology, Fukui Prefectural University, Fukui 9101195, Japan

Full list of author information is available at the end of the article

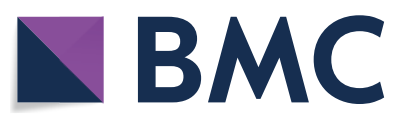

(c) The Author(s) 2021. Open Access This article is licensed under a Creative Commons Attribution 4.0 International License, which permits use, sharing, adaptation, distribution and reproduction in any medium or format, as long as you give appropriate credit to the original author(s) and the source, provide a link to the Creative Commons licence, and indicate if changes were made. The images or other third party material in this article are included in the article's Creative Commons licence, unless indicated otherwise in a credit line to the material. If material is not included in the article's Creative Commons licence and your intended use is not permitted by statutory regulation or exceeds the permitted use, you will need to obtain permission directly from the copyright holder. To view a copy of this licence, visit http://creativecommons.org/licenses/by/4.0/. The Creative Commons Public Domain Dedication waiver (http://creativeco mmons.org/publicdomain/zero/1.0/) applies to the data made available in this article, unless otherwise stated in a credit line to the data. 
Conclusions: The present results indicated that C. hypnaeoides was able to alleviate HF diet-induced metabolic disorders, including obesity, hyperglycemia, hepatic steatosis, and hypercholesterolemia by attenuating inflammation and improving the antioxidant capacity in mice. Polysaccharides and polyphenols may be involved in these beneficial effects of C. hypnaeoides.

Keywords: Obesity, Diabetes, Hepatic steatosis, Seaweed, Campylaephora hypnaeoides J. Agardh, Polysaccharide, Oxidative stress, Inflammation

\section{Introduction}

The prevalence of obesity has increased worldwide over the past decades. Obesity is a chronic and complex metabolic disease and is defined as a condition of abnormal or excessive fat accumulation in adipose tissue resulting in impaired health [1]. A lack of physical activity, sedentary lifestyle and energy-rich diet are the main causes of obesity. It is well established that obesity is the main risk factor for a number of non-communicable diseases, including type II diabetes, dyslipidemia, cardiovascular disease, hypertension, coronary heart disease, and certain types of cancers [2-4].

Seaweed has few calories and contains many different ingredients necessary for maintaining health, including minerals, vitamins, polysaccharides, polyunsaturated fatty acids, inorganic elements, and polyphenols [5]. Animal experiments have revealed the beneficial effects of seaweed and seaweed components on the prevention of diseases, including cardiovascular disease, metabolic disorders, neurodegenerative disease, and cancer $[5,6]$. For example, various types of polysaccharides present in seaweed exhibit diverse biological and pharmacological activities, including antioxidant, immunomodulatory, anticoagulant, antitumor, antiviral and hypolipidemic activities $[7,8]$. Furthermore, recent studies have shown that seaweed polysaccharides are resistant to gastrointestinal enzyme digestion and serve as fermentation substrates for intestinal microbial populations [9]. Seaweed is a rich source of phenolic compounds. The phenolic derivatives also exhibit a broad spectrum of biological properties, including antioxidant, anti-inflammatory, antimicrobial, anticancer, antidiabetic, and anti-obesity activities $[10,11]$. These active components have been investigated for their potential use in food, cosmetic, and pharmaceutical applications [12]. Seaweed has long been used as an ingredient in Japanese food and is considered to be an ingredient that has supported the health and longevity of Japanese people. Epidemiological evidences among the Japanese indicates that the intake of seaweed is associated with a lower incidence of cardiovascular disease mortality $[13,14]$. We previously demonstrated that some Japanese seaweeds prevented the development of metabolic disorders, such as obesity, diabetes, dyslipidemia, and hepatic steatosis in mice fed an HF diet [15].
Campylaephora hypnaeoides J. Agardh (C. hypnaeoides), an edible red seaweed also known as Egonori in Japan, grows along the coast of the Japan Sea. C. hypnaeoides is rich in polysaccharides, and after being boiled and hardened, it has long been eaten as a local dish in various parts of Japan. It is also used as a raw material for agar. We previously demonstrated that a $70 \%$ ethanol extract of $C$. hypnaeoides suppressed postprandial hyperglycemia by inhibiting the activity of carbohydrate-degrading enzymes [16]. It also ameliorated the high glucose-induced overproduction of reactive oxygen species and cell apoptosis through anti-oxidant and anti-inflammatory effects in cultured human umbilical vein endothelial cells [16]. Although a detailed analysis of constituents has not been performed, C. hypnaeoides is known to be rich in polysaccharides and polyphenols. From the results of these previous studies, C. hypnaeoides is expected to be useful for the prevention of metabolic disorders such as obesity and diabetes. The present study was carried out to determine the effects of C. hypnaeoides on the development of obesity and related metabolic disease in mice fed an HF diet.

\section{Methods}

\section{The purification and molecular mass analysis} of polysaccharides

The extraction of polysaccharides was performed according to a previously described method by a previously described procedure [17]. Briefly, $200 \mathrm{mg}$ of powdered seaweed was incubated in $20 \mathrm{ml}$ of $85 \%$ ethanol at $80{ }^{\circ} \mathrm{C}$ for $4 \mathrm{~h}$ to remove lipids. This extraction operation was repeated three times. Polysaccharides in the residue were extracted with $30 \mathrm{ml}$ of cold water, dialyzed against distilled water, and then freeze-dried $(32.0 \mathrm{mg})$. The total sugar content was determined by phenol-sulfuric acid method using galactose as a standard [18]. The sulfate content was determined by the $\mathrm{BaCl}_{2}$-gelatin method [19] using K-carrageenan (TCI, Tokyo, Japan) as a positive control. The relative molecular weight of the polysaccharides was determined by high-performance size exclusion chromatography with Shodex OHpak SB807G (Guard), SB-807 HQ, and SB-806 M HQ (8.0 mm ID $\times 300 \mathrm{~mm}$ length; Showa Denko KK, Tokyo, Japan) at $40{ }^{\circ} \mathrm{C}$ and estimated using dextran standards $(150,270$, 
and $670 \mathrm{kDa}$ from Sigma Aldrich Corp., 3,755 kDa from American Polymer Standards Corp., Mentor, OH, USA). Sample (injected volume: $20 \mu \mathrm{l}$ ) was eluted using $0.3 \mathrm{M}$ $\mathrm{NaNO}_{3}$ at a flow rate of $1 \mathrm{ml} / \mathrm{min}$ and was detected using a refractive index (RI) detector RID10 (Shimadzu Corp., Kyoto, Japan).

\section{Preparation of polyphenol extract and measurement of polyphenols}

Powdered C. hypnaeoides were extracted with $80 \%$ ethanol at room temperature for $48 \mathrm{~h}$. The ethanol extract was filtered and concentrated using a rotary evaporator. Total polyphenols were determined by a previously reported method with slight modifications [20]. Phenolic extract $(10 \mu \mathrm{l})$ was placed in triplicate in a 96 -well plate, and mixed with $25 \mu \mathrm{l}$ of $1 \mathrm{~N}$ Folin-Ciocalteu reagent and $20 \%$ sodium bicarbonate, followed by $150 \mu \mathrm{l}$ distilled water. The mixture was incubated for $30 \mathrm{~min}$ at room temperature before recording the absorbance at $630 \mathrm{~nm}$. Total polyphenol was calculated according to the gallic acid standard curve. The total polyphenol content in ethanol extract was $9.65 \mathrm{mg}$ gallic acid equivalent $/ \mathrm{g}$.

\section{Animals and dietary treatment}

Male C57BL/6 J mice (6-week-old) were purchased from CLEA Japan Inc. (Tokyo, Japan) and housed at a constant temperature of $22 \pm 1{ }^{\circ} \mathrm{C}$ with a $12 \mathrm{~h}$ light/dark cycle. After 1 week of acclimation, the animals were randomly divided into 4 groups of 12-13 animals, as follows: (1) normal diet (normal) group, high-fat (HF) diet group, HF diet supplemented with $2 \%$ C. hypnaeoides $(\mathrm{HF}+\mathrm{ChL})$ group, and HF supplemented with $6 \% C$. hypnaeoides $(\mathrm{HF}+\mathrm{ChH})$ group. The doses of $C$. hypnaeoides were decided based on the previous studies [15]. The $C$. hypnaeoides sample was harvested on the coast of Niigata Prefecture and was washed with water. It was dried, reduced to a fine powder using a food mixer, and mixed into HF chow. The composition of the experimental diets was adjusted by considering the nutritional components of C. hypnaeoides as described previously [15]. The normal diet provided $354 \mathrm{kcal} / 100 \mathrm{~g}$ of energy $(14.4 \%$ calories from protein, $11.1 \%$ calories from fat and $74.4 \%$ calories from carbohydrate), while the HF diet provided $493 \mathrm{kcal} / 100 \mathrm{~g}$ of energy (17.9\% calories from protein, $60.7 \%$ calories from fat and $21.4 \%$ calories from carbohydrate). All experimental diets were based on the AIN-76 diet (Oriental Yeast Co. Ltd., Tokyo, Japan). Animals were allowed ad libitum access to food and drinking water. The food, including the HF diet was exchanged with new food every day. The body weight and food intake were monitored twice a week. After 13 weeks of feeding, the mice were deprived of food overnight, and blood samples were withdrawn under mixed anesthetic agent $(0.3 \mathrm{mg} / \mathrm{kg}$ of medetomidine, $4.0 \mathrm{mg} / \mathrm{kg}$ of midazolam, and $5.0 \mathrm{mg} / \mathrm{kg}$ of butorphanol; Fujifilm Wako Pure Chemical Co., Osaka, Japan). Liver tissue and epididymal, peritoneal, and mesenteric white adipose tissues were removed, weighed, and stored at $-80{ }^{\circ} \mathrm{C}$. Some mice were used for histological examinations. All experimental protocols were approved by the Institutional Animal Care and Use Committee of Fukui Prefectural University (Approval No. 19-14).

\section{Serum biochemical analyses}

Serum was obtained by centrifugation at $1500 \times g$ for $15 \mathrm{~min}$ at $4{ }^{\circ} \mathrm{C}$. The serum levels of total cholesterol, high-density lipoprotein (HDL)-cholesterol, triglyceride, alanine aminotransferase (ALT) and aspartate aminotransferase (AST) were analyzed using a Hitachi 7060 Automatic Analyzer (Hitachi, Tokyo, Japan) with commercial kits (Fujifilm Wako Pure Chemical Co., Osaka, Japan). The serum insulin (Morinaga Institute of Biological Science, Yokohama, Japan), adiponectin (Otsuka Pharmaceutical Co. Ltd. Tokyo, Japan), tumor necrosis factor- $\alpha$ (TNF- $\alpha$; Fujifilm Wako Pure Chemical Co., Osaka, Japan), and monocyte chemoattractant protein-1 (MCP-1; Proteintech, Rosemont, IL, USA) levels were also determined using a commercial ELISA kit. Serum malondialdehyde (MDA) levels were determined using a commercial kit (Japan Institute for the Control of Aging Co. Ltd., Shizuoka, Japan). The homeostasis model assessment insulin resistance (HOMA-IR), an insulin resistance index, was calculated using the following equation: $\mathrm{HOMA}-\mathrm{IR}=$ fasting glucose $(\mathrm{mg} / \mathrm{dL}) \times$ fasting insulin $(\mathrm{ng} / \mathrm{mL}) / 22.5$.

\section{Hepatic biochemical analysis}

Lipids were extracted from the liver according to a previously described method [21]. In brief, frozen liver tissues (50 mg) were homogenized in 5 volumes of isopropanol. The homogenate was kept at room temperature for 2 days and then centrifuged at $1000 \times g$ for $10 \mathrm{~min}$. Aliquots of supernatant were analyzed for triglyceride content using a commercial kit (Fujifilm Wako Pure Chemical Co., Osaka, Japan). Liver samples for the biochemical analysis were homogenized in 5 volumes of cold $20 \mathrm{mM}$ Tris- $\mathrm{HCl}$ buffer ( $\mathrm{pH} 7.4$ ), and centrifuged at $12,000 \times g$ for $15 \mathrm{~min}$ at $4{ }^{\circ} \mathrm{C}$. The supernatant was used for the biochemical analysis. Lipid peroxidation was determined by estimating malondialdehyde (MDA) using a commercial kit (Japan Institute for the Control of Aging Co. Ltd., Shizuoka, Japan). The reduced glutathione (GSH) levels were determined using a commercial kit (Japan Institute for the Control of Aging Co. Ltd., Shizuoka, Japan). The inflammatory cytokine levels in the liver were quantified using enzyme-linked immunosorbent assay (ELISA) kits specific for mouse TNF- $\alpha$ and interleukin-6 (IL-6). (Fujifilm 
Wako Pure Chemical Co., Osaka, Japan). The protein concentration was determined using a Quick Start Bradford protein assay (Bio-Rad Laboratories, Inc., Hercules, CA, USA).

\section{Histological analyses}

The mice were anesthetized with an intraperitoneal injection of mixed anesthetic agent $(0.3 \mathrm{mg} / \mathrm{kg}$ of medetomidine, $4.0 \mathrm{mg} / \mathrm{kg}$ of midazolam, and $5.0 \mathrm{mg} / \mathrm{kg}$ of butorphanol; Fujifilm Wako Pure Chemical Co., Osaka, Japan), and transcardially perfused with a fixative containing $4 \%$ paraformaldehyde and $1.5 \%$ glutaraldehyde in phosphate-buffered saline (PBS). After perfusion, the liver and white adipose tissue were removed and allowed to stand in the same fixative for one day. The tissues were rinsed several times with PBS and embedded in paraffin. Tissues were cut into 5 - $\mu$ m-thick sections, mounted on slides, and stained with hematoxylin eosin (HE).

\section{Glucose tolerance test}

A glucose loading test was performed one week before the end of experiment to access glucose intolerance [22]. The mice were fasted overnight and intraperitoneally injected with glucose ( $2 \mathrm{~g} / \mathrm{kg}$ body weight). Blood samples were collected from the tail veins of the mice, and glucose levels were measured at 0, 30, 60, 90, and $120 \mathrm{~min}$ after injection using a blood glucometer Nipro Stat Strip (Nipro, Osaka, Japan).

\section{Fecal analyses}

During fecal collection, mice were separated, and fecal samples were collected for a 24-h period from each mouse and weighed. These samples were ground into a powder in a mortar, and $50 \mathrm{mg}$ of feces was extracted with $300 \mu \mathrm{l}$ of distilled water. After centrifugation $\left(16,000 \times g, 30 \mathrm{~min}, 4^{\circ} \mathrm{C}\right)$, ethanol was added to the supernatant (final concentration of $85 \%$ ), and polysaccharides were obtained as the precipitate. The resulting residue was washed with $85 \%$ ethanol and dried. The residue was then resuspended in distilled water and centrifuged $\left(16,000 \times g, 10 \mathrm{~min}, 4{ }^{\circ} \mathrm{C}\right)$, and the polysaccharide content in the supernatant was measured using the phenol-sulfuric acid method, which has been described elsewhere, with galactose as the standard [18]. For the measurement of triglycerides, lipids were extracted by adding isopropanol (10 times the weight) to the fecal powder. The sample was then dried and dissolved in isopropanol. The triglyceride concentration was measured using a commercial kit (Fujifilm Wako Pure Chemical Co., Osaka, Japan).

\section{Nitric oxide and cytokine assays}

RAW264.7 cells were prepared to a concentration of $2 \times 10^{5}$ cells $/ \mathrm{ml}$ using MEM medium (M5650, Sigma Aldrich) supplemented with $10 \%$ fetal bovine serum and antibiotics (penicillin $100 \mathrm{U} / \mathrm{ml}$ and streptomycin $100 \mu \mathrm{l} /$ $\mathrm{ml}$ ) The cell suspension was added to a 96-well plate and cultured in a $5 \% \mathrm{CO}_{2}$ incubator for $24 \mathrm{~h}$. After washing each well with phosphate-buffered saline, lipopolysaccharide (LPS; derived from Escherichia coli O111, Fujifilm Wako Pure Chemical Co., Osaka, Japan) with a final concentration of $100 \mathrm{ng} / \mathrm{mL}$ and polysaccharide or ethanol extract solution were added to the medium. The cells were cultured in a $5 \% \mathrm{CO}_{2}$ incubator for an additional $24 \mathrm{~h}$. The culture supernatant $(100 \mu \mathrm{l})$ was collected, $100 \mu \mathrm{l}$ of Griess reagent was added, and the mixture was left for $20 \mathrm{~min}$ in the dark; the absorbance was then measured by microplate reader at $543 \mathrm{~nm}$. The nitric oxide concentration in the medium was calculated from the standard curve prepared from sodium nitrite. Cell viability was evaluated via a 3- (4,5-dimethylthial-2-yl) -2,5-diphenyltetrazalium bromide (MTT) colorimetric assay.

\section{Statistical analysis}

Results are expressed as the mean \pm SEM. Data were analyzed by a one-way analysis of variance (ANOVA) followed by Turkey's multiple range tests. $P$ values of $p<0.05$ were considered to indicate statistical significance.

\section{Results}

\section{Isolation of polysaccharide}

The yield of the obtained C. hypnaeoides polysaccharides was $16.0 \%$. It showed a symmetric peak on high-performance size exclusion chromatography and the molecular mass was estimated to be $1.4 \times 10^{5} \mathrm{Da}$. The polysaccharides contained $95.8 \%$ sugar and $3.3 \%$ sulfate. The sulfate content of C. hypnaeoides was much lower than that of K-carrageenan (17.8\%), which was used as a positive control.

\section{Food intake and body weight}

The addition of $2 \%$ or $6 \%$ C. hypnaeoides to an HF diet did not affect the amount of food consumption. The average daily food intake of each group throughout the experimental period was as follows: $3.1 \mathrm{~g}$ (Normal), $2.5 \mathrm{~g}(\mathrm{HF}), 2.5 \mathrm{~g}(\mathrm{HF}+\mathrm{ChL})$, and $2.6 \mathrm{~g}(\mathrm{HF}+\mathrm{ChH})$. The energy intake of mice in the normal group was not significantly different from that of mice in the HF group (12.1 vs. $12.8 \mathrm{kcal} / \mathrm{mouse} /$ day). HF diet feeding to mice for 13 weeks induced marked body weight gain, which was double that of normal mice (Table 1). The body weights began to differ significantly between the HF 
Table 1 The effects of C. hypnaeoides on the body weight gain and serum metabolic parameters in C57BL/6 J mice fed a highfat diet

\begin{tabular}{lcccc}
\hline Variables & Normal & HF & HF + ChL & HF + ChH \\
\hline $\begin{array}{l}\text { Body weight } \\
\text { gain }\end{array}$ & $12.3 \pm 3.5$ & $24.8 \pm 1.9^{\# \#}$ & $21.6 \pm 3.7^{*}$ & $20.4 \pm 2.1^{*}$ \\
$\begin{array}{l}\text { Glucose (mg/ } \\
\text { dL) }\end{array}$ & $97 \pm 13$ & $155 \pm 12^{\# \#}$ & $104 \pm 13^{* *}$ & $98 \pm 15^{* *}$ \\
Insulin (ng/mL) & $0.51 \pm 0.14$ & $2.50 \pm 0.90^{\# \#}$ & $0.80 \pm 0.32^{* *}$ & $0.63 \pm 0.05^{* *}$ \\
HOMA-IR & $3.45 \pm 1.3$ & $26.9 \pm 8.1^{\# \#}$ & $5.76 \pm 2.3^{* *}$ & $4.32 \pm 0.51^{* *}$ \\
TC (mg/dL) & $98 \pm 19$ & $187 \pm 8^{\# \#}$ & $173 \pm 27$ & $169 \pm 7^{*}$ \\
HDL-C (mg/dL) & $58 \pm 16$ & $70 \pm 7$ & $73 \pm 3$ & $71 \pm 4$ \\
TG (mg/dL) & $47 \pm 16$ & $35 \pm 9$ & $39 \pm 11$ & $34 \pm 6$ \\
ALT (IU/L) & $24 \pm 9$ & $96 \pm 27^{\# \#}$ & $51 \pm 35^{*}$ & $52 \pm 20^{* *}$ \\
AST (IU/L) & $89 \pm 13$ & $130 \pm 29^{\# \#}$ & $111 \pm 24$ & $102 \pm 19^{*}$ \\
\hline
\end{tabular}

HOMA-IR homeostatic model assessment-insulin resistance, TC total cholesterol, $H D L-C$ high-density lipoprotein cholesterol, TG triglyceride, $A L T$ alanine aminotransferase, AST aspartate aminotransferase

Data were expressed as mean $\pm S D(n=6-12)$. Statistical significance: ${ }^{\# \#} p<0.01$ vs. Normal group, ${ }^{*} p<0.05,{ }^{* *} p<0.01$ versus HF group

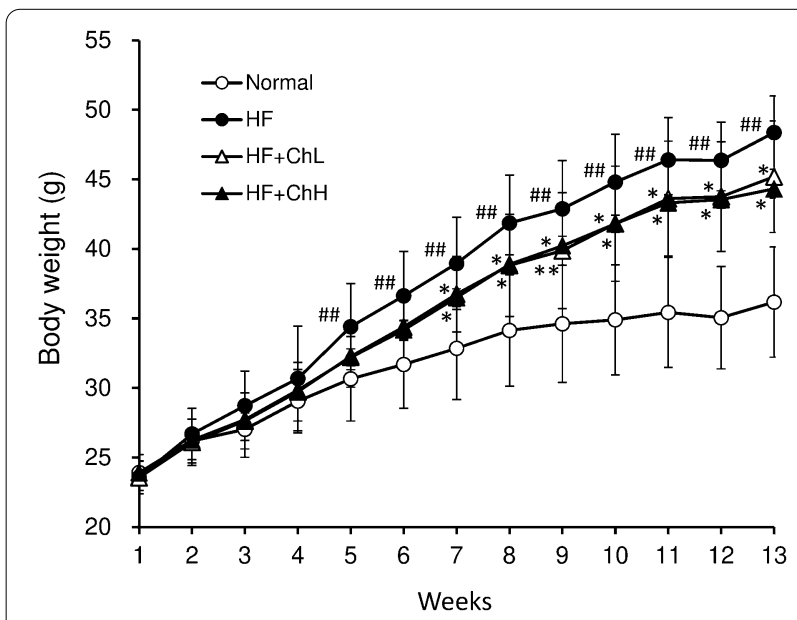

Fig. 1 The effects of C. hypnaeoides on body weight in C57BL/6J mice fed a high-fat diet. Normal, normal diet; $\mathrm{HF}$, high-fat diet; $\mathrm{HF}+\mathrm{ChL}$, high-fat diet mixed with $2 \% \mathrm{C}$. hypnaeoides; $\mathrm{HF}+\mathrm{ChH}$, high-fat diet mixed with $6 \% \mathrm{C}$. hypnaeoides. Each value represents the mean $\pm S D(n=12-13)$. Statistical significance: ${ }^{*} p<0.05$ vs. HF group, $\# p<0.01$ versus Normal group

group and the normal group after 5 weeks of treatment, and between the $\mathrm{HF}$ group and $\mathrm{HF}+\mathrm{ChH}$ group after 7 weeks of treatment (Fig. 1). At the end of experiment, the body weight of both the $\mathrm{HF}+\mathrm{ChL}$ and $\mathrm{HF}+\mathrm{ChH}$ groups was significantly lower in comparison to the mice in the HF group.

\section{Body fat}

The weight of each adipose tissue (epididymal, retroperitoneal, and mesenteric) was significantly higher in the HF group than that in the normal group (Fig. 2A). The weight of total adipose tissue in the HF group was also significantly higher than that in the normal group. Thirteen-week-treatment of HF mice with C. hypnaeoides significantly reduced the total tissue weight and the weight of each adipose tissue (Fig. 2A). A histological analysis showed that adipocytes in HF mice were hypertrophic in comparison to those in normal mice (Fig. 2C). The diameter of adipocytes was significantly increased by administration of an HF diet. (Fig. 2B).In contrast, the adipocyte size was decreased by $C$. hypnaeoides supplementation (Fig. 2B, C).

Serum levels of glucose and insulin, and insulin resistance Although the ingestion of an HF diet increased the serum levels of glucose and insulin, C. hypnaeoides supplementation significantly suppressed the elevation of glucose and insulin levels (Table 1). The effects of C. hypnaeoides supplementation on insulin resistance were determined using a glucose tolerance test. The blood glucose levels in C. hypnaeoides-supplemented mice were lower at 15, 30, 60 , and $90 \mathrm{~min}$ after the intraperitoneal administration of glucose, in comparison to mice in the HF group (Fig. 3A). The area under the curve (AUC) for glucose was also significantly lower in $C$. hypnaeoides-supplemented mice in comparison to mice in the HF group (Fig. 3B). The HOMA-IR value, which is an index of insulin resistance, was markedly increased by ingestion of an HF diet, but was ameliorated by $C$. hypnaeoides supplementation (Table 1).

\section{Hepatic lipid accumulation and serum liver function parameters}

The feeding an HF diet to mice for 13 weeks markedly increased the liver triglyceride content, which was accompanied by an increase in liver weight (Fig. 4A, B). In HF diet-fed mice, supplementation with $C$. hypnaeoides suppressed the increase in liver weight and hepatic triglyceride content (Fig. 4A, B). In addition, elevated serum liver function parameters, including alanine aminotransferase (ALT) and aspartate aminotransferase (AST) were decreased by supplementation with C. hypnaeoides (Table 1). The gross morphology of the liver showed that the liver of the mice in the HF group was larger and exhibited a paler color in comparison to the mice in the normal group (Fig. 4C). A histological examination revealed hepatic steatosis in the liver of mice in the HF group, as evidenced by vacuoles, lipid droplets, 


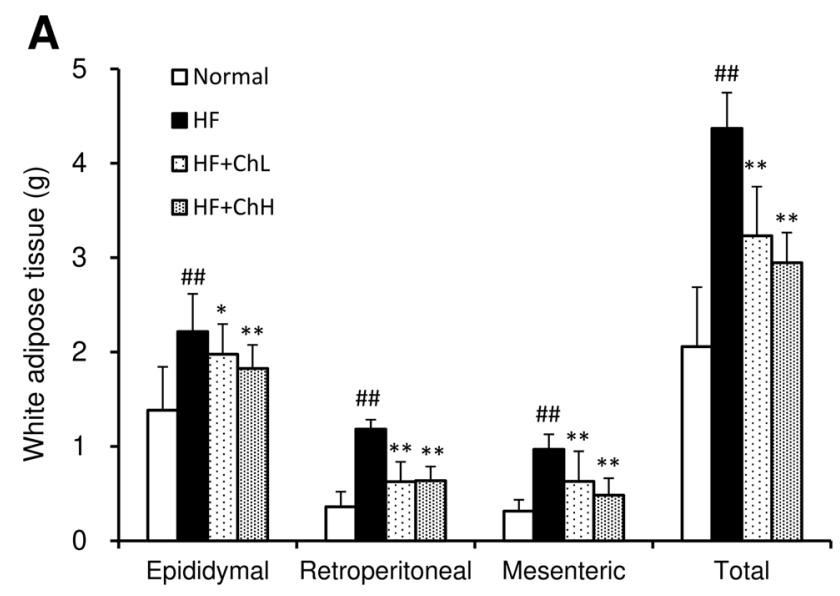

B
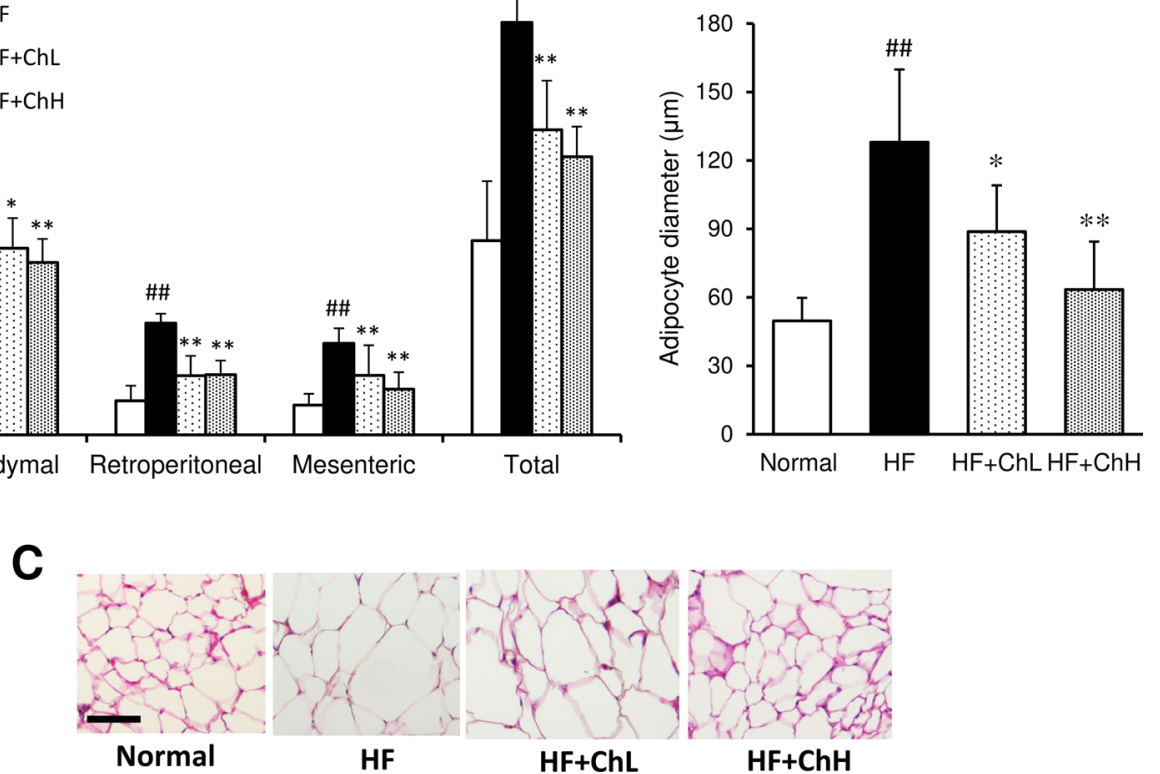

Fig. 2 The effects of C. hypnaeoides on the mass and morphology of white adipose tissue in C57BL/6J mice fed a high-fat diet. After the mice were sacrificed, the mass of the epididymal, retroperitoneal, and mesenteric white adipose tissue was determined (A). Adipose tissue was fixed and the section of epididymal adipose tissue was stained with hematoxylin and eosin (C). The average diameter of adipocytes was determined (B). Normal, normal diet; HF, high-fat diet; HF + ChL, high-fat diet mixed with 2\% C. hypnaeoides; HF + ChH, high-fat diet mixed with 6\% C. hypnaeoides. Each value represents the mean $\pm S D(n=8)$. Statistical significance: ${ }^{*} p<0.05,{ }^{* *} p<0.01$ versus HF group, ${ }^{\# \#} p<0.01$ versus Normal group. Scale $\operatorname{bar}=100 \mu \mathrm{m}$

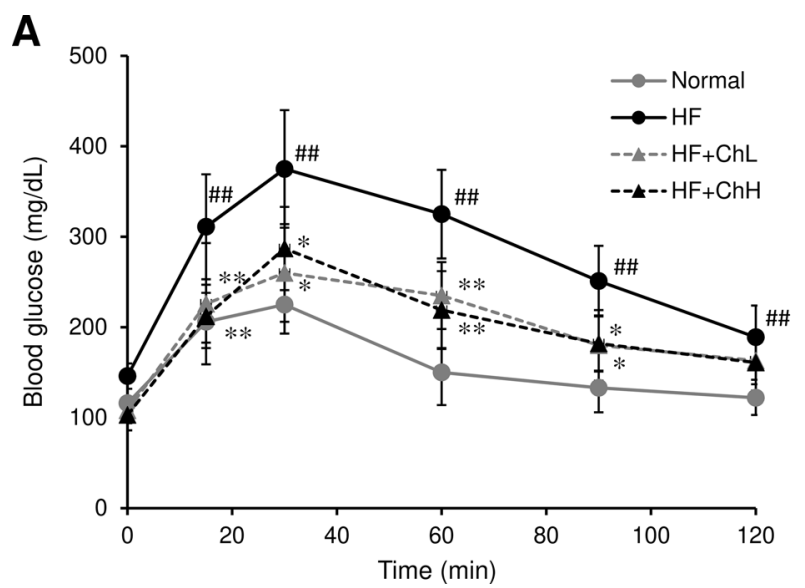

\section{B}

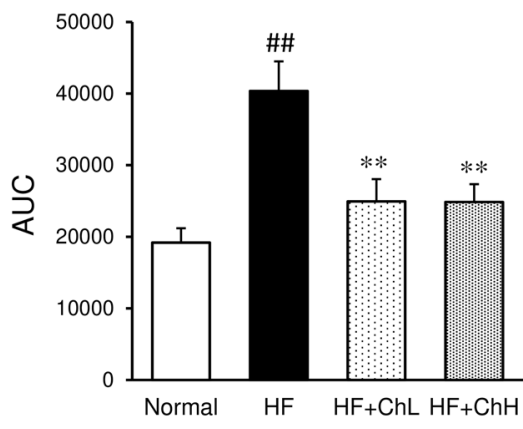

Fig. 3 The effects of C. hypnaeoides on the insulin resistance in C57BL/6J mice fed a high-fat diet. Insulin resistance was evaluated by a glucose tolerance test in the 12th week after high-fat diet ingestion (A), and the area under the curve (AUC) was calculated (B). Normal, normal diet; HF, high-fat diet; HF + ChL: high-fat diet mixed with 2\% C. hypnaeoides; HF + ChH: high-fat diet mixed with 6\% C. hypnaeoides. Each value represents the mean \pm SD $(n=6-8)$. Statistical significance: ${ }^{*} p<0.05,{ }^{* *} p<0.01$ versus HF group, ${ }^{\# \#} p<0.01$ versus Normal group

and hepatocyte swelling (Fig. 4D). The development of HF-induced hepatic steatosis was ameliorated by C. hypnaeoides supplementation.

\section{Hepatic parameters of oxidative stress and inflammation} The feeding an HF diet to mice increased the hepatic levels of malondialdehyde (MDA), an oxidative stress marker, while it decreased the hepatic levels of 

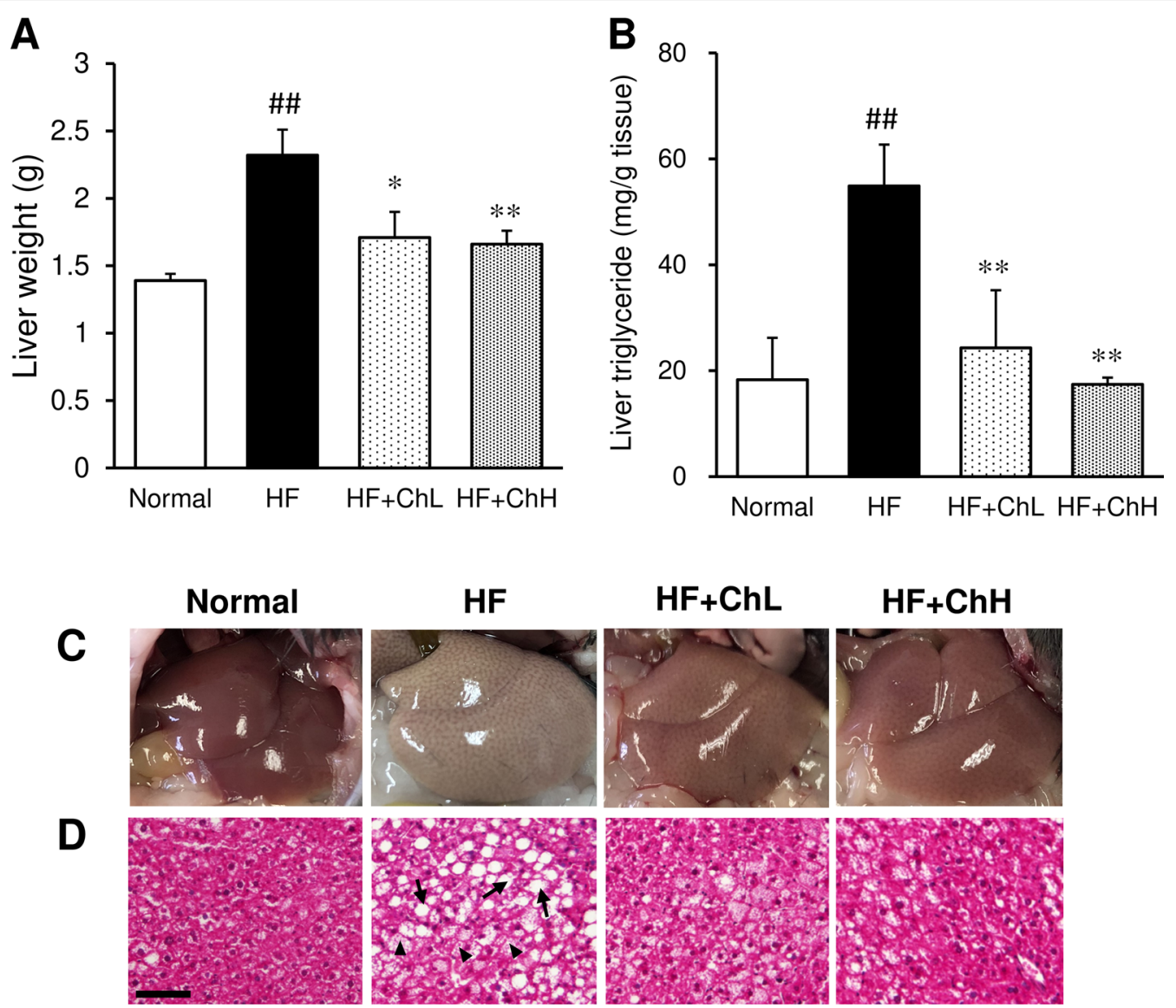

Fig. 4 The effects of C. hypnaeoides on the hepatic lipid accumulation in C57BL/6J mice fed a high-fat diet. A Liver weight, B Triglyceride content, C Representative gross morphology, D Histological sections of the liver. Normal, normal diet; HF, high-fat diet; HF + ChL, high-fat diet mixed with $2 \%$ C. hypnaeoides; $\mathrm{HF}+\mathrm{ChH}$, high-fat diet mixed with $6 \% \mathrm{C}$. hypnaeoides. Each value represents the mean $\pm \mathrm{SD}(\mathrm{n}=6-8)$. Arrows indicate lipid droplets, and arrow heads indicate hepatocyte swelling. Statistical significance: ${ }^{*} p<0.05,{ }^{* *} p<0.01$ versus HF group, ${ }^{\# \#} p<0.01$ versus Normal group. Scale bar $=100 \mu \mathrm{m}$

anti-oxidant defense markers, glutathione (GSH) and superoxide dismutase (SOD) (Table 2). An HF diet also increased hepatic levels of pro-inflammatory cytokines, TNF- $\alpha$ and IL-6 (Table 2). These changes in hepatic parameters recovered with $C$. hypnaeoides supplementation in a dose-dependent manner.

\section{Serum parameters of oxidative stress and inflammation}

Consistent with the effects of C. hypnaeoides on hepatic parameters of oxidative stress and inflammation, the HF-induced elevation of serum MDA, TNF$\alpha$, and monocyte chemoattractant protein-1 (MCP-1) levels was ameliorated by $C$. hypnaeoides supplementation in a dose-dependent manner (Table 2). In addition, the HF-induced decrease in serum adiponectin levels was suppressed by C. hypnaeoides (Table 2).

\section{Serum lipid levels}

The ingestion of an HF diet markedly increased levels of serum total cholesterol, which was significantly suppressed by a high dose of C. hypnaeoides (Table 1). Similar to previous study, the feeding of an HF diet had no significant effects on the serum levels of HDL cholesterol or triglyceride (Table 1) [15]. C. hypnaeoides supplementation also had no effect on these lipids.

\section{Fecal levels of lipids and polysaccharides}

The fecal weight and fecal polysaccharide content were significantly increased by $C$. hypnaeoides supplementation (Fig. 5A, C). Although the HF increased the fecal triglyceride content, C. hypnaeoides supplementation had no effects (Fig. 5B). 
Table 2 The effects of C. hypnaeoides on the oxidant, anti-oxidant, and inflammatory markers of the serum and liver in C57BL/6 J mice fed a high-fat diet

\begin{tabular}{llclc}
\hline Variables & Normal & HF & HF + ChL & HF + ChH \\
\hline Serum & & & & \\
MDA $(\mathrm{nmol} / \mathrm{mL})$ & $1.51 \pm 0.17$ & $2.64 \pm 0.47^{\# \#}$ & $2.11 \pm 0.31^{*}$ & $1.85 \pm 0.37^{* *}$ \\
adiponectin $(\mu \mathrm{g} / \mathrm{mL})$ & $22.8 \pm 0.97$ & $16.2 \pm 1.4^{\# \#}$ & $16.7 \pm 3.0$ & $20.9 \pm 1.8^{*}$ \\
TNF-a $(\mathrm{pg} / \mathrm{mL})$ & $4.21 \pm 1.4$ & $10.66 \pm 3.3^{\# \#}$ & $8.93 \pm 1.7$ & $5.93 \pm 2.1^{*}$ \\
MCP-1 $(\mathrm{pg} / \mathrm{mL})$ & $32.7 \pm 5.8$ & $45.0 \pm 9.7^{\#}$ & $35.2 \pm 7.3^{*}$ & $26.4 \pm 5.9^{*}$ \\
Liver & & & & \\
MDA (nmol/mg protein) & $6.53 \pm 1.3$ & $16.1 \pm 4.3^{\# \#}$ & $11.3 \pm 2.8^{*}$ & \\
GSH (nmol/mg protein) & $81.8 \pm 15$ & $59.3 \pm 18^{\#}$ & $65.3 \pm 18$ & \\
SOD (U/mg protein) & $8.34 \pm 1.5$ & $5.54 \pm 1.5^{\# \#}$ & $6.21 \pm 2.3$ & $7.2 \pm 13^{*}$ \\
TNF-a (pg/mg protein) & $5.14 \pm 1.2$ & $12.35 \pm 3.2^{\# \#}$ & & $9.15 \pm 3.3^{*}$ \\
IL-6 (pg/mg protein) & $1.47 \pm 0.21$ & $2.18 \pm 0.45^{\# \#}$ & $1.99 \pm 0.44$ & $6.51 \pm 1.4^{* *}$ \\
\hline
\end{tabular}

MDA malondialdehyde, TNF- $a$ tumor necrosis factor $a, M C P-1$ monocyte chemoattractant protein-1, GSH glutathione, SOD superoxide dismutase

Data were expressed as mean \pm SD $(n=6-8)$. Statistical significance: ${ }^{\#} p<0.05$, ${ }^{\#} p<0.01$ versus Normal group, ${ }^{*} p<0.05,{ }^{* *} p<0.01$ versus HF group

\section{Nitric oxide and TNF-a production in RAW264.7 cells}

The anti-inflammatory effects of polysaccharides isolated from C. hypnaeoides were assessed in macrophage RAW264.7 cells. The addition of polysaccharides to the culture medium suppressed the lipopolysaccharide (LPS)-induced production of nitric oxide (NO) and TNF- $\alpha$ in a dose-dependent manner (Fig. 6A, B). Ethanol extract also suppressed the LPS-induced production of NO and TNF- $\alpha$ (Fig. $6 \mathrm{C}, \mathrm{D})$.

\section{Discussion}

The present study showed that an edible red seaweed, $C$. hypnaeoides exhibited an anti-obesity effect in mice fed a high-fat (HF) diet, as was evident from the reduced body weight gain and reduced body fat accumulation. In addition, $C$. hypnaeoides ameliorated obesity-associated metabolic disorders, including insulin resistance, hyperglycemia, hepatic steatosis, and hypercholesterolemia. The beneficial effects of $C$. hypnaeoides were associated with a reduction of oxidative stress and inflammation. It is well documented that oxidative stress and inflammation are closely involved in various kinds of diseases, including obesity and obesity-related noncommunicable diseases [23]. The excessive intake of major nutrients such as an HF diet activates metabolic signaling pathways, including c-Jun $\mathrm{N}$-terminal kinase (JNK) and nuclear factor- $\kappa \mathrm{B}$ (NF- $\kappa \mathrm{B})$, and leads to the induction of inflammatory cytokines, resulting in a low-grade inflammatory response. A wide variety of naturally occurring compounds and extracts have been shown to ameliorate obesity, diabetes, and hepatic steatosis through anti-oxidative and anti-inflammatory effects [24, 25], although there is fewer information from studies in humans in comparison to studies using animal models [26].
Adipose tissue is not merely a simple reservoir of energy stored as triglycerides, it also serves as an active secretory organ releasing many physiologically active substances, referred to as adipokines, into the circulation [27]. During the development of obesity, adipocytes become hypertrophic and the balance between adipokines is altered. Hypertrophic adipocytes produce more pro-inflammatory adipokines, such as TNF- $\alpha$ and IL-6, and fewer anti-inflammatory adipokines, such as adiponectin in comparison to normal adipocytes [28]. In addition, inflammatory cells such as leukocytes, macrophages, and T-cells recruit the surrounding adipocytes with lipid accumulation in adipocytes. Monocyte chemoattractant protein-1 (MCP-1) is produced by macrophages and endothelial cells and is a potent chemotactic factor for monocytes [29]. Circulating levels of TNF- $\alpha$ and IL- 6 have been shown to be correlated with increasing adipose mass [30]. The plasma level and adipose tissue expression of MCP-1 have also been found to be increased in obese humans [31] and animals [32] in comparison to lean controls. Elevated circulating pro-inflammatory adipokines induce peripheral insulin resistance [33]. Adiponectin is a major anti-inflammatory adipokine, which is produced exclusively by adipocytes and which exhibits a wide range of biological activities, including anti-inflammatory, insulin-sensitizing, anti-atherogenic, and cardioprotective properties [34]. The circulating levels of adiponectin in obese patients and patients with diabetes are lower in comparison to healthy volunteers [35]. A negative association between serum adiponectin levels and the body mass index has been reported in diabetic patients. Therefore, a decrease in serum adiponectin levels predicts the development of metabolic disorders, such as insulin resistance and type 

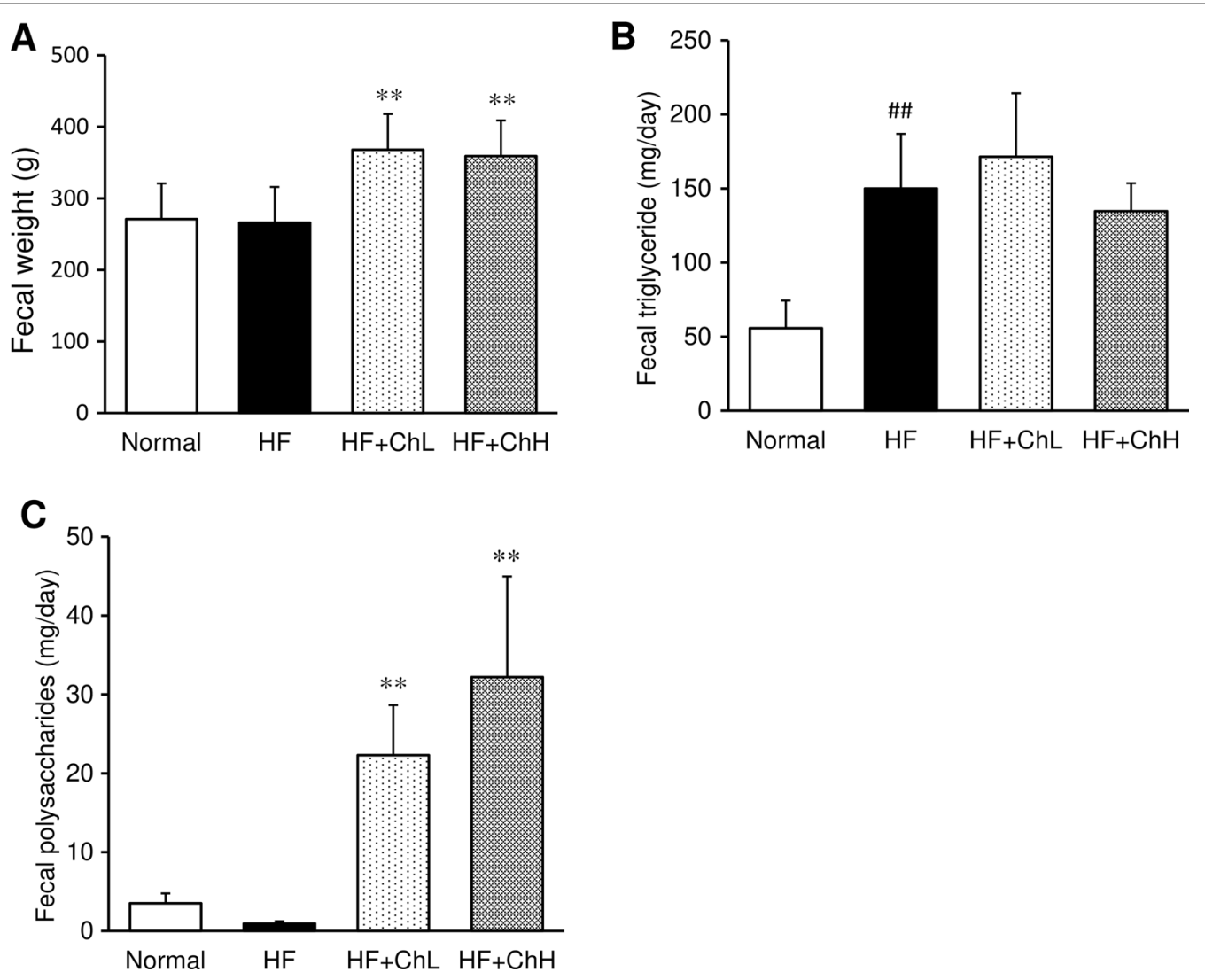

Fig. 5 The effects of C. hypnaeoides on the fecal weight and fecal components in C57BL/6J mice fed a high-fat diet. Feces samples were collected from each mouse after high-fat diet ingestion for 10 weeks, and the fecal weight was measured (A). The triglyceride (B) and polysaccharides (C) content were determined after extraction with isopropanol and distilled water, respectively. Normal, normal diet; HF, high-fat diet; $\mathrm{HF}+\mathrm{ChL}$, high-fat diet mixed with $2 \%$ C. hypnaeoides; HF + ChH, high-fat diet mixed with 6\% C. hypnaeoides. Each value represents the mean $\pm S D(n=7)$. Statistical significance: ${ }^{* *} p<0.01$ versus HF group, ${ }^{\# \#} p<0.01$ versus Normal group

II diabetes [36]. Consistent with these previous observations, the serum levels of TNF- $\alpha$, IL-6, and MCP-1 were elevated in obese mice fed an HF diet, while the level of adiponectin was decreased. The treatment of obese mice with $C$. hypnaeoides recovered serum adipokines to the normal levels in a dose-dependent manner. In addition, C. hypnaeoides suppressed the HF-induced elevation of both TNF- $\alpha$ and IL- 6 levels in the liver. An elevated inflammation response is known to be related to the onset and development of metabolic disorders other than obesity, including insulin resistance, diabetes, hepatic steatosis, and atherosclerosis. Thus, the anti-inflammatory action is one possible mechanism by which C. hypnaeoides ameliorated metabolic diseases in HF-induced obese mice.

Reactive oxygen species (ROS) play an important role in physiological cellular processes, and their imbalance and excessive production leads to oxidative stress, followed by damage to biomolecules such as lipids, proteins, and DNA [37]. Biologically, the body employs a range of antioxidant defense system to counter excessive oxidative stress, which includes superoxide dismutase (SOD) and catalase. Glutathione is a major non-protein antioxidant that protects cells against oxidative injury by scavenging ROS. Reduced glutathione levels are associated with the pathogenesis of many diseases, including liver disease and diabetes [38]. It has been shown that obese individuals exhibit higher levels of oxidative stress in adipose tissue, including elevated ROS production and decreased antioxidant activity [39]. In the present study, hepatic and serum levels of MDA, a biomarker of oxidative stress, were markedly elevated in obese mice, while hepatic glutathione and SOD levels were reduced in the liver of obese mice in comparison to normal mice, suggesting increased oxidative stress and a decreased antioxidant defense system. The treatment of obese mice with C. hypnaeoides reduced the MDA levels and increased the glutathione and SOD in the liver in a dose-dependent manner. These findings indicate that oxidative stress was increased in obese mice and that $C$. hypnaeoides 

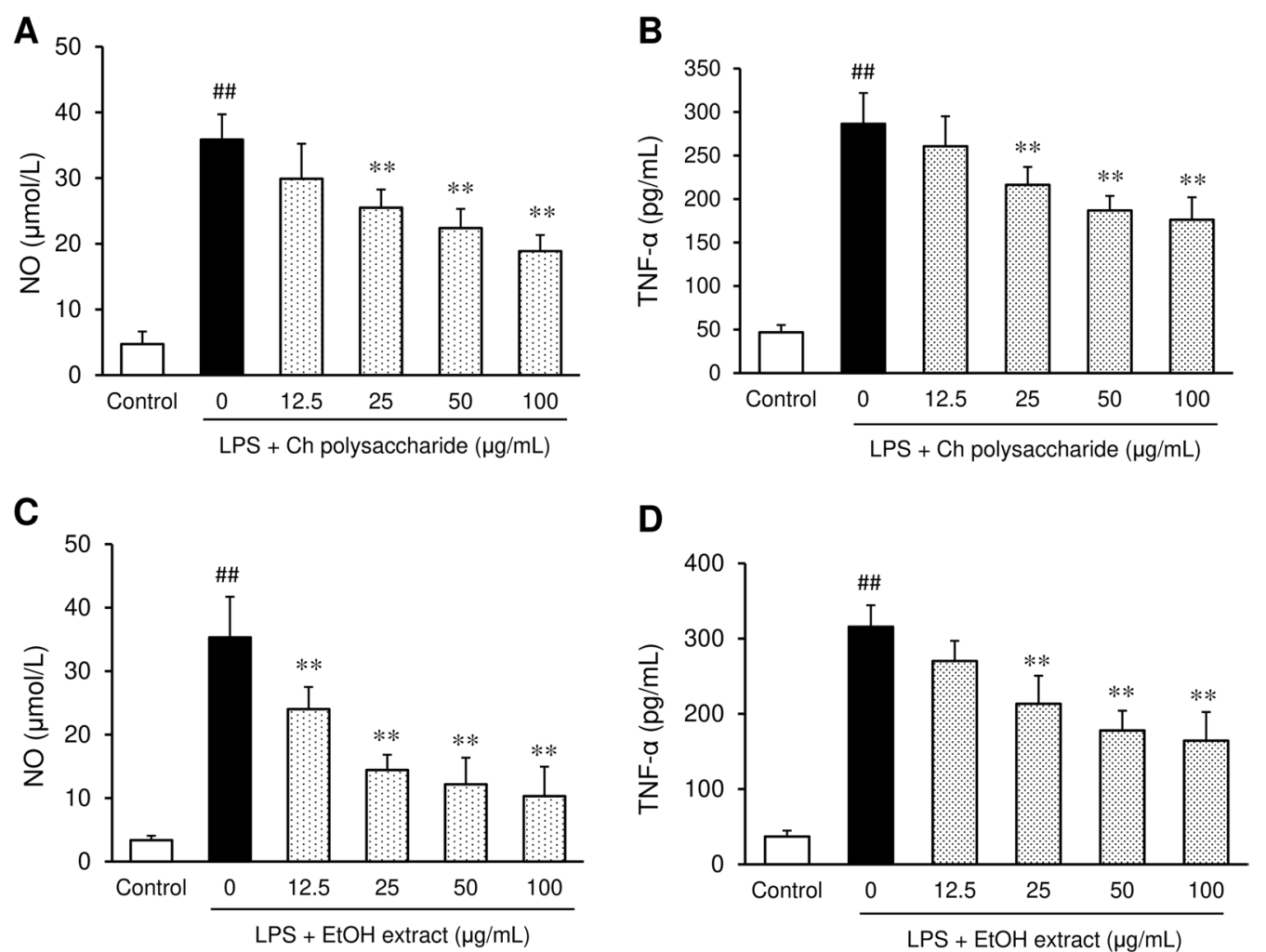

Fig. 6 The effects of $C$. hypnaeoides polysaccharides and ethanol extract on the production of nitric oxide (A, C) and TNF-a (B, D) in RAW 264.7 cells. Each values represents the mean $\pm S D(n=6)$. Statistical significance: ${ }^{* *} p<0.01$ versus $L P S+C h$ polysaccharides $(0 \mu \mathrm{g} / \mathrm{ml})$ or $\mathrm{LPS}+\mathrm{EtOH}$ extract $(0 \mu \mathrm{g} / \mathrm{ml}),{ }^{\# \#} p<0.01$ versus Control

ameliorated obesity and obesity-related metabolic disorders through an antioxidative mechanism. We have previously demonstrated the anti-inflammatory and antioxidant actions of $70 \%$ ethanol extract of $C$. hypnaeoides in cultured cells and in vitro [16]. Ethanol extract of $C$. hypnaeoides containing rich polyphenols exhibited a potent anti-oxidative effect and inhibited cell apoptosis via the suppression of ROS production in human umbilical vein endothelial cells. It also inhibited lipopolysaccharide (LPS)-induced nitric oxide (NO) production in RAW 264.7 cells, indicating anti-oxidant and anti-inflammatory activity. The present study showed that polysaccharides isolated from C. hypnaeoides suppressed LPS-induced production of NO and TNF- $\alpha$ in RAW264.7 cells. These results suggest that polysaccharide and polyphenol may be involved in the anti-oxidant and anti-inflammatory mechanisms by which $C$. hypnaeoides improved metabolic dysfunction.

We have previously shown that extracts of some seaweeds inhibited the activity of pancreatic lipase and suppressed the absorption of triglyceride. As a result, the fecal triglyceride content was increased [15]. As pancreatic lipase is a key enzyme that catalyzes the hydrolysis of triglyceride to monoacylglycerols and fatty acids, the inhibition of this enzyme activity results in reduced lipid absorption and subsequent amelioration of body fat accumulation. The treatment of mice in the HF group with $C$. hypnaeoides had no significant effects on fecal triglyceride content, suggesting that the inhibition of intestinal lipid absorption is not involved in the anti-obesity effect of C. hypnaeoides.

\section{Conclusion}

In summary, this study showed that the Japanese traditional edible seaweed C. hypnaeoides, ameliorated obesity, hyperglycemia, hepatic steatosis, and hypercholesterolemia in obese mice fed an HF diet. The beneficial effects of C. hypnaeoides on HF-induced metabolic disorders were associated with reduced oxidative stress and inflammation. Polysaccharides and polyphenols may play an important role in preventing these disorders. The possible effects of $C$. hypnaeoides in obese and diabetic individuals need to be further investigated. 


\section{Abbreviations}

ALT: Alanine aminotransferase; AST: Aspartate aminotransferase; AUC: Area under the curve; C. hypnaeoides: Campylaephora hypnaeoides J. Agardh; HF: High-fat diet; GSH: Glutathione; HDL: High-density lipoprotein; IL-6: Interleukin-6; MDA: Malondialdehyde; MCP-1: Monocyte chemoattractant protein-1; NO: Nitric oxide; ROS: Reactive oxygen species; SOD: Superoxide dismutase; TNF-a: Tumor necrosis factor-a.

\section{Acknowledgements}

We gratefully acknowledge the Inokai Co. Ltd and Echigo Ego Preservation Society (Nagaoka, Japan) for providing Campylaephora hypnaeoides J.Agardh and related information.

\section{Authors' contributions}

SM designed the study. $\mathrm{CH}, \mathrm{RY}, \mathrm{TM}, \mathrm{TO}, \mathrm{TI}, \mathrm{NM}, \mathrm{TI}$, and $\mathrm{CM}$ participated in data acquisition and analysis. SM and CM wrote the manuscript. All authors read and approved the final manuscript.

\section{Funding}

This research was supported by a grant for scientific research from Fukui Prefectural University (01-02R010201)

\section{Availability of data and materials}

The datasets used and/or analyzed during the current study are available from the corresponding author on reasonable request.

\section{Declarations}

\section{Ethics approval and consent to participate}

All the experimental protocols for animals were approved by the Institutiona Animal Care and Use Committee of Fukui Prefectural University (Approval No. 19-14).

\section{Consent for publication}

Not applicable.

\section{Competing interests}

The authors declare no competing interest in association with the present study.

\section{Author details}

1 Department of Bioscience and Biotechnology, Fukui Prefectural University, Fukui 9101195, Japan. ²Division of Health Science, Graduate School of Health Science, Suzuka University, Mie 5100293, Japan. ${ }^{3}$ Ishikawa Prefecture Fisheries Division, Ishikawa 9208580, Japan. ${ }^{4}$ Research Institute for Bioscience and Biotechnology, Ishikawa Prefectural University, Ishikawa 9218836, Japan.

Received: 13 September 2021 Accepted: 30 November 2021 Published online: 08 January 2022

\section{References}

1. Heymsfield SB, Wadden TA. Mechanisms, pathophysiology, and management of obesity. N Engl J Med. 2017;376:254-66.

2. Kahn SE, Hull RL, Utzschneider KM. Mechanisms linking obesity to insulin resistance and type 2 diabetes. Nature. 2006:444:840-6.

3. Van Gaal LF, Mertens IL, De Block CE. Mechanisms linking obesity with cardiovascular disease. Nature. 2006;444:875-80.

4. Hopkins BD, Goncalves MD, Cantley LC. Obesity and cancer mechanisms: cancer metabolism. J Clin Oncol. 2016;34:4277-83.

5. Brown ES, Allsopp PJ, Magee PJ, Gill Cl, Nitecki S, Strain CR, McSorley EM. Seaweed and human health. Nutr Rev. 2014;71:205-16.

6. Cherry P, O'Hara C, Magee PJ, McSorley EM, Allsopp PJ. Risks and benefits of consuming edible seaweeds. Nutr Rev. 2019;77:307-29.

7. de Jesus Raposo MF, de Morais AM, de Morais RM. Marine polysaccharides from algae with potential biomedical applications. Mar Drugs. 2015;13:2967-3028

8. Xu SY, Huang X, Cheong KL. Recent advances in marine algae polysaccharides: Isolation, structure, and activities. Mar Drugs. 2017;15:388.
9. Lopez-Santamarina A, Miranda JM, Mondragon ADC, Lamas A, CardelleCobas A, Franco CM, Cepeda A. Potential use of marine seaweeds as prebiotics. Molecules. 2020;25:1004.

10. Thomas NV, Kim SK. Potential pharmacological applications of polyphenolic derivatives from marine brown algae. Environ Toxicol Pharmacol. 2011;32:325-35.

11. Montero L, Del Pilar S-C, Ibáñez E, Gilbert-López B. Phenolic compounds from edible algae: bioactivity and health benefits. Curr Med Chem. 2018:25:4808-26.

12. Cotas J, Leandro A, Monteiro P, Pacheco D, Figueirinha A, Gonçalves AMM da Silva GJ, Pereira L. Seaweed phenolics: From extraction to applications. Mar Drugs. 2020;18:384.

13. Murai U, Yamagishi K, Sata M, Kokubo Y, Saito I, Yatsuya H, Ishihara J, Inoue M, Sawada N, Iso H, Tsugane S; JPHC Study Group. Seaweed intake and risk of cardiovascular disease: the Japan Public Health Center-based Prospective (JPHC) Study. Am J Clin Nutr. 2019;110:1449- 55.

14. Kishida R, Yamagishi K, Muraki I, Sata M, Tamakoshi A, Iso H; JACC Study Group. Frequency of seaweed intake and its association with cardiovascular disease mortality: the JACC Study. J Atheroscler Thromb. 2020:27:1340-47.

15. Murakami S, Hirazawa C, Ohya T, Yoshikawa R, Mizutani T, Ma N, Moriyama M, Ito T, Matsuzaki C. The edible brown seaweed Sargassum horneri (Turner) C. Agardh ameliorates high-fat diet-induced obesity, diabetes, and hepatic steatosis in mice. Nutrients. 2021;13:551.

16. Murakami S, Kimura K, Kawasaki A, Ono A, Mizutani T, Sugiura A, Hirazawa C, Yada T, Sinki J, Ito T. The edible red alga Egonori (Campylaephora hypnaeoides J. Agardh) alleviates postprandial blood glucose level and high glucose-induced endothelial dysfunction. Nippon Shokuhin Kagaku Kogaku Kaishi. 2020;67:257-63.

17. Hu Y, Yu G, Zhao X, Wang Y, Sun X, Jiao G, Zhao X, Chai W. Structural characterization of natural ideal 6-O-sulfated agarose from red alga Gloiopeltis furcata. Carbohydr Polym. 2012;89:883-9.

18. DuBois M, Gilles KA, Hamilton JK, Rebers PA, Smith F. Colorimetric method for determination of sugars and related substances. Anal Chem. 1956;28:350-6.

19. Ji CF, Ji YB, Meng DY. Sulfated modification and anti-tumor activity of laminarin. Exp Ther Med. 2013;6:1259-64.

20. Dia VP, Wang Z, West M, Singh V, West L, de Mejia EG. Processing method and corn cultivar affected anthocyanin concentration from dried distillers grains with solubles. J Agric Food Chem. 2015;63:3205-18.

21. Murakami S, Yamagishi I, Sato M, Tomisawa K, Nara Y, Yamori Y. ACAT inhibitor HL-004 accelerates the regression of hypercholesterolemia in stroke-prone spontaneously hypertensive rats (SHRSP): stimulation of bile acid production by HL-004. Atherosclerosis. 1997;133:97-104.

22. Andrikopoulos S, Blair AR, Deluca N, Fam BC, Proietto J. Evaluating the glucose tolerance test in mice. Am J Physiol Endocrinol Metab. 2008;295:E1323-32.

23. Rani V, Deep G, Singh RK, Palle K, Yadav UC. Oxidative stress and metabolic disorders: pathogenesis and therapeutic strategies. Life Sci. 2016;148:183-93.

24. Alam MA, Subhan N, Rahman MM, Uddin SJ, Reza HM, Sarker SD. Effect of citrus flavonoids, naringin and naringenin, on metabolic syndrome and their mechanisms of action. Adv Nutr. 2014;5:404-17.

25. Yahfoufi N, Alsadi N, Jambi M, Matar C. The Immunomodulatory and antiinflammatory role of polyphenols. Nutrients. 2018;10:1618.

26. Amiot MJ, Riva C, Vinet A. Effects of dietary polyphenols on metabolic syndrome features in humans: a systematic review. Obes Rev. 2016;17:573-86.

27. Sethi JK, Vidal-Puig AJ. Thematic review series: adipocyte biology. Adipose tissue function and plasticity orchestrate nutritional adaptation. J Lipid Res. 2007:48:1253-62.

28. Rajala MW, Scherer PE. Minireview: the adipocyte- at the crossroads of energy homeostasis, inflammation, and atherosclerosis. Endocrinology. 2003;144:3765-73.

29. Kanda H, Tateya S, Tamori Y, Kotani K, Hiasa K, Kitazawa R, Kitazawa S, Miyachi H, Maeda S, Egashira K, Kasuga M. MCP-1 contributes to macrophage infiltration into adipose tissue, insulin resistance, and hepatic steatosis in obesity. J Clin Invest. 2006;1 16:1494-505.

30. Bastard JP, Jardel C, Bruckert E, Blondy P, Capeau J, Laville M, Vidal H, Hainque $B$. Elevated levels of interleukin 6 are reduced in serum and 
subcutaneous adipose tissue of obese women after weight loss. J Clin Endocrinol Metab. 2000;85:3338-42.

31. Catalán V, Gómez-Ambrosi J, Ramirez B, Rotellar F, Pastor C, Silva C, Rodríguez A, Gil MJ, Cienfuegos JA, Frühbeck G. Proinflammatory cytokines in obesity: impact of type 2 diabetes mellitus and gastric bypass. Obes Surg. 2007;17:1464-74.

32. Miyazawa M, Subbaramaiah K, Bhardwaj P, Zhou XK, Wang H, Falcone DJ, Giri DD, Dannenberg AJ. Pioglitazone inhibits periprostatic white adipose tissue inflammation in obese mice. Cancer Prev Res (Phila). 2018:11:215-26

33. Taniguchi CM, Emanuelli B, Kahn CR. Critical nodes in signalling pathways: insights into insulin action. Nat Rev Mol Cell Biol. 2006;7:85-96.

34. Matsuzawa Y. Adiponectin: a key player in obesity related disorders. Curr Pharm Des. 2010;16:1896-901.

35. Ghadge AA, Khaire AA, Kuvalekar AA. Adiponectin: a potential therapeutic target for metabolic syndrome. Cytokine Growth Factor Rev. 2018;39:151-8.

36. Kim HS, Jo J, Lim JE, Yun YD, Baek SJ, Lee TY, Huh KB, Jee SH. Adiponectin as predictor for diabetes among pre-diabetic groups. Endocrine. 2013:44:411-8.

37. Forrester SJ, Kikuchi DS, Hernandes MS, Xu Q, Griendling KK. Reactive oxygen species in metabolic and inflammatory signaling. Circ Res. 2018;122:877-902.

38. Rolo AP, Teodoro JS, Palmeira CM. Role of oxidative stress in the pathogenesis of nonalcoholic steatohepatitis. Free Radic Biol Med. 2012;52:59-69.

39. Furukawa S, Fujita T, Shimabukuro M, Iwaki M, Yamada Y, Nakajima Y, Nakayama O, Makishima M, Matsuda M, Shimomura I. Increased oxidative stress in obesity and its impact on metabolic syndrome. J Clin Invest. 2004;114:1752-61.

\section{Publisher's Note}

Springer Nature remains neutral with regard to jurisdictional claims in pub-

lished maps and institutional affiliations.

- fast, convenient online submission

- thorough peer review by experienced researchers in your field

- rapid publication on acceptance

- support for research data, including large and complex data types

- gold Open Access which fosters wider collaboration and increased citations

- maximum visibility for your research: over 100M website views per year

At BMC, research is always in progress.

Learn more biomedcentral.com/submissions 